Conclusions: Idiopathic NIHF, is a very serious condition with high fetal mortality and limited effective therapy, so prevention is very crucial. APS prophylaxis regimen, based on anti-platelets and anti-coagulant therapy during pregnancy, may have promising effects.

Disclosure of Interest: None declared

DOI: 10.1136/annrheumdis-2018-eular.5798

\section{AB1161 FAMILIAL MEDITERRANEAN FEVER AS AN OUTCOME OF UNDIFFERENTIATED ARTHRITIS}

V. Vardanyan ${ }^{1}$, K. Ginosyan ${ }^{1}$, A. Simonyan ${ }^{1}$, S. Bakhshyan ${ }^{2} .{ }^{1}$ Internal Medicine Yerevan State Medical University; "Cito" Medical Centre, Yerevan, Armenia

Background: The term «undifferentiated arthritis» (UA) was proposed to emphasise the heterogeneity of unclassifiable arthritides and their potential into a definable form of arthritis. A patient with UA have an early stage of defined arthritis that will meet criteria in time, a forme fruste or partial form of a classifiable disease, an overlap of more than one disease entity, or an arthritis of unknown or in that may (or may not) become differentiated in the future. The heterogeneity associated with the term "UA» emphasises the need for continued follow-up and reassessment of the diagnosis and management of these patients.

Objectives: The aim of this study was revelation of MEFV gene mutations in patients with UA.

Methods: We have examined 80 patients (34 male, 46 female, mean age 36,4 \pm 3.4 years) with UA. The patients were observed every 6 months in follow-up period of 5 years. The anamnestic and treatment data were obtained. Joint disease activity scores and presence of extra-articular manifestations were determined. The $\mathrm{CBC}$, urinalysis, serum concentrations of creatinine, bilirubin, transaminases, glucose, CRP were determined every 6 months, X-ray examination and ultrasonography of joints were performed once a year. Molecular-genetic analysis of 12 MEFV-mutations, common for Armenians, were carried out in Medical Genetic Centre of Armenia.

Results: From 80 investigated patients with UA 10 had repeated episodes of mono- and oligoarthritis of ankle and/or knee joints with local skin hyperemia and hyperthermia, without subsequent joint deformities, 45 - sacroiliitis (26 bilateral, 19 unirateral), accompanied by enthesopathy, 2 - joint syndrome, resembling rheumatoid arthritis. In 23 patients joint syndrome was accompanied by erythema rash, livedo reticularis, photosensitivity and alopecia. The latter group of patients was diagnosed as SLE-like syndrome. All patients didn't fulfil accepted classification criteria of any autoimmune or autoinflammatory disease. The $80 \%$ of investigated patients had no classic febrile attacks of abdominalgia and/or thoracalgia, specific for FMF. In remaining $20 \%$ of patients febrile attacks hadn't preceded joint syndrome, but appeared during 5 year follow-up period.

All investigated patients had MEFV gene mutations, which's compositions (homozygous or compound heterozygous) were enough to confirm Familial Mediterranean Fever (FMF). The most common mutations were: M694V-41.2\%, V726A$18.8 \%$, M680I-10\%. The most common compositions were M694V/M694V, M694V/V726A, M694V/M680I

Conclusions: As FMF is widely distributed in Mediterranean region, and it had changed its phenotype in last decades, as well as taking into account the increasing rate of migration worldwide, every single case of UA, which doesn't fulfil classification criteria of any disease, should be tested for presence of MEFV-mutations. The diagnosis of FMF changes the approach to follow-up, management, outcome and prognosis of UA

Disclosure of Interest: None declared

DOI: 10.1136/annrheumdis-2018-eular.3682

\section{AB1162 DIAGNOSTIC UTILITY OF LYMPH NODE BIOPSY IN DIFFERENTIAL DIAGNOSIS OF IGG4-RELATED DISEASE, IDIOPATHIC MULTICENTRIC CASTLEMAN'S DISEASE AND PRIMARY DISSEMINATED MALT- LYMPHOMA}

V. Vasilyev $^{1}$, E. Sokol ${ }^{1}$, S. Palshina ${ }^{1}$, B. Chaltsev ${ }^{1}$, N. Probatova ${ }^{2}$ A. Pavlovskaya ${ }^{2}$, N. Kokosadze ${ }^{2}$, A. Kovrigina ${ }^{3}$, T. Safonova $^{1}$, I. Gayduk ${ }^{4}$ ${ }^{1}$ Nasonova Research Institute of Rheumatology, Moscow, Russia; ${ }^{2}$ N.N. Blokhin Russian Cancer Research Center, ${ }^{3}$ National Hematology Research Center, ${ }^{4}$ Moscow State University of Medicine and Dentistry, Moscow, Russian Federation

Background: Lymphadenopathy $(\mathrm{LA})$ is a frequent and challenging syndrome in rheumatic patients. It requires comprehensive clinical and expert pathological evaluation. IgG4-related disease (IgG4-RD) combines a group of fibroinflammatory conditions characterised by formation of tumor-like lesions with unique morphological features and hyper-IgG4 secretion in different organs and tissues. LA is frequent in IgG4-RD and doesn't have a unique morphology. Idiopathic multicentric Castleman's disease (iMCD) is a rare lymphoprolipherative disorder of a hyper-IL-6 spectrum with obligate lymph nodes (LN) affection and less frequent extranodal lesions. Pathologic features of the LN in iMCD overlap with IgG4-LA and there can be $\lg G 4$ hypersecretion in iMCD patients as well. Primary disseminated MALT-Iymphomas (DMALT) are also in the spectrum of differential diagnosis because of the involvement of salivary and lacrimal glands.

Objectives: To evaluate the diagnostic utility of LN biopsy in differential diagnosis of IgG4-RD, iMCD and DMALT.

Methods: Retrospective study. We reviewed medical records from 2009 to 2017 and identified 13 pts. who were examined in our clinic due to some rheumatological diagnosis suspicion and whose leading symptom at the onset of the disease was LA. All patients had prior multiple LN biopsy ( $25 \mathrm{LN}$ biopsies in total) which was reviewed by an expert pathologist during our examination. 11 pts. had extranodal lesions and underwent extranodal biopsy.

Results: Eight pts. were men, 5 women with average age at the onset 34,7 years (15-71 years). The directional diagnoses established on the LN pathology were as following (in some cases a few diagnosis): iMCD (4 pts), non-Hodgkin lymphoma ( 3 pts), reactive LN (12 pts). 11 pts. had some extranodal lesions (3,9 per patient, from 1 to 8 ): orbit -8 , major salivary glands -8 , hepatosplenomegaly -5 lungs -5 , thyroid -5 , kidneys -3 , sinusitis -3 , skin, cholangitis -2 each, retroperitoneum, mediastinum, pancreas and soft tissues -1 each. Due to orbital and major salivary glands involvement some patients had directional diagnosis of Sjogren's syndrome or IgG4-RD. In all 13 pts. the directional diagnosis was changed to some other based on the extranodal biopsy pathology results (in 11 pts) and/or clinical presentation (in 2 pts with isolated LA). LN pathology was not conclusive in all cases. In all cases LN phathology fell into I-IV type of LN morphological picture as reported by J. Ferry et al. ${ }^{1}$ Clinical presentation in 13 pts see in table 1. The final diagnosis were: IgG4-RD in 7 pts, iMCD in 2 pts and DMALT in 4 pts.

Abstract AB1162 - Table 1. Clinical-laboratory features of patients

\begin{tabular}{|c|c|c|c|}
\hline & IgG4-RD (n=7) & $\operatorname{iMCD}(n=2)$ & DMALT $(\mathrm{n}=4)$ \\
\hline $\begin{array}{l}\text { Median age at the onset, } \\
\text { years }\end{array}$ & 26 & 17 & 49 \\
\hline $\begin{array}{l}\text { Constitutional symptoms, } \\
\mathrm{N}(\%)\end{array}$ & $1(14)$ & $2(100)$ & $1(25)$ \\
\hline Orbit involvement, $\mathrm{N}(\%)$ & $4(57)$ & $0(0)$ & $4(100)$ \\
\hline $\begin{array}{l}\text { Major salivary glands } \\
\text { involvement, } \mathrm{N}(\%)\end{array}$ & $4(57)$ & $0(0)$ & $4(57)$ \\
\hline Atopic, N $(\%)$ & $4(57)$ & $0(0)$ & $0(0)$ \\
\hline Extranodal lesions, $\mathrm{N}(\%)$ & $7(100)$ & $1(50)$ & $4(100)$ \\
\hline Blood eosinophilia, N (\%) & $4(57)$ & $0(0)$ & $0(0)$ \\
\hline $\begin{array}{l}\text { Blood thrombocytosis, N } \\
(\%)\end{array}$ & $0(0)$ & $2(100)$ & $0(0)$ \\
\hline $\begin{array}{l}\text { Elevation of IL-6 }>2 \mathrm{~N}, \mathrm{~N} \\
(\%)\end{array}$ & $0(0)$ & $2(100)$ & $1(25)$ \\
\hline $\begin{array}{l}\text { Elevation of CRP }>2 \mathrm{~N}, \mathrm{~N} \\
(\%)\end{array}$ & $0(0)$ & $2(100)$ & $0(0)$ \\
\hline $\begin{array}{l}\text { Serum IgG4 }>200 \mathrm{mg} / \mathrm{dl}, \\
\mathrm{N}(\%)\end{array}$ & $7(100)_{-}$ & $2(100)$ & $0(0)$ \\
\hline $\begin{array}{l}\text { Auto antibodies (ANA, } \\
\text { RF, anti-SSA } / \text { Ro), N }(\%)\end{array}$ & $3(43)$ & $0(0)$ & $1(25)$ \\
\hline $\begin{array}{l}\text { Hypocomplemenemia, N } \\
(\%)\end{array}$ & $3(43)$ & $0(0)$ & $1(25)$ \\
\hline $\begin{array}{l}\text { Serum monodonal } \\
\text { secretion, } \mathrm{N}(\%)\end{array}$ & $1(14)$ & $0(0)$ & $3(75)$ \\
\hline $\begin{array}{l}\text { B-cell donality in the } \\
\text { tissue, } \mathrm{N}(\%)\end{array}$ & $0(0)$ & $0(0)$ & $4(100)$ \\
\hline $\begin{array}{l}\text { Tissue IgG } 4+/ \mathrm{IgG}+ \\
\text { plasma cells }>40 \%, \mathrm{~N}(\%)\end{array}$ & $7(100)$ & $0(0)$ & $0(0)$ \\
\hline
\end{tabular}

Conclusions: It seems to be very challenging to set a reliable differential diagnosis based on the LN pathology thus extranodal biopsy is preferable. Orbital and major salivary glands involvement is a feature of IgG4-RD or DMALT, but not iMCD. Prominent constitutional symptoms with high laboratory inflammatory markers (CRP, IL-6) are characteristic of iMCD.

\section{REFERENCE:}

[1] Ferry, J. IgG4-related lymphadenopathy and IgG4-related lymphoma: moving targets//Diagnostic Histipathology. - 2013.- Vol. 19.—№ 4.-P. 128139

Disclosure of Interest: None declared DOI: 10.1136/annrheumdis-2018-eular 7318

\section{AB1163 MY BEHCET'S DISEASE AND MY MENSTRUATION CYCLE: OBSERVATION FROM AN IRISH COHORT}

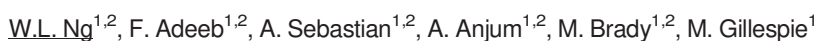
F. Irwin ${ }^{2}$, B. McCarthy ${ }^{2}$, J. Devlin ${ }^{1,2}$, A. Fraser ${ }^{1,2} .{ }^{1}$ Rheumatology, University Hospital Limerick; ${ }^{2}$ Rheumatology, Croom Orthopaedic Hospital, Limerick, Ireland

Background: The menstrual cycle is regulated by the rise and fall of sex hormones in the body. Literature has demonstrated anti-inflammatory properties in both progesterone and oestrogen hormones. ${ }^{1}$ There has been recent interest to determine the association between Behçet's Disease (BD), a poorly understood autoinflammatory disorder and menstruation. 